\title{
Electrophysiological evaluation of phrenic nerve injury during cardiac surgery - a prospective, controlled, clinical study Suat Canbaz*1, Nilda Turgut ${ }^{2}$, Umit Halici ${ }^{1}$, Kemal Balci ${ }^{2}$, Turan Ege ${ }^{1}$ and Enver Duran ${ }^{1}$
}

\author{
Address: ${ }^{1}$ Department of Cardiovascular Surgery, Trakya University, Medical Faculty, Edirne, Turkey and ${ }^{2}$ Department of Neurology, Trakya \\ University, Medical Faculty, Edirne, Turkey \\ Email: Suat Canbaz* - scanbaz2001@yahoo.com; Nilda Turgut - nildaturgut@trakya.edu.tr; Umit Halici - umithalici@trakya.edu.tr; \\ Kemal Balci - kbalci@trakya.edu.tr; Turan Ege - turanege@ttnet.net.tr; Enver Duran - eduran@superonline.com \\ * Corresponding author
}

Published: 14 January 2004

BMC Surgery 2004, 4:2
Received: 23 August 2003

Accepted: 14 January 2004

This article is available from: http://www.biomedcentral.com/I47I-2482/4/2

(C) 2004 Canbaz et al; licensee BioMed Central Ltd. This is an Open Access article: verbatim copying and redistribution of this article are permitted in all media for any purpose, provided this notice is preserved along with the article's original URL.

\begin{abstract}
Background: According to some reports, left hemidiaphragmatic paralysis due to phrenic nerve injury may occur following cardiac surgery. The purpose of this study was to document the effects on phrenic nerve injury of whole body hypothermia, use of ice-slush around the heart and mammary artery harvesting.

Methods: Electrophysiology of phrenic nerves was studied bilaterally in 78 subjects before and three weeks after cardiac or peripheral vascular surgery. In 49 patients, coronary artery bypass grafting (CABG) and heart valve replacement with moderate hypothermic (mean $28^{\circ} \mathrm{C}$ ) cardiopulmonary bypass (CPB) were performed. In the other 29, CABG with beating heart was performed, or, in several cases, peripheral vascular surgery with normothermia.

Results: In all patients, measurements of bilateral phrenic nerve function were within normal limits before surgery. Three weeks after surgery, left phrenic nerve function was absent in five patients in the CPB and hypothermia group ( 3 in CABG and 2 in valve replacement). No phrenic nerve dysfunction was observed after surgery in the CABG with beating heart (no CPB) or the peripheral vascular groups. Except in the five patients with left phrenic nerve paralysis, mean phrenic nerve conduction latency time $(\mathrm{ms})$ and amplitude $(\mathrm{mV})$ did not differ statistically before and after surgery in either group $(p>0.05)$.

Conclusions: Our results indicate that CPB with hypothermia and local ice-slush application around the heart play a role in phrenic nerve injury following cardiac surgery. Furthermore, phrenic nerve injury during cardiac surgery occurred in $10.2 \%$ of our patients (CABG with CPB plus valve surgery).
\end{abstract}

\section{Background}

Phrenic nerve injury is a well-known clinical condition following cardiac surgery [1-5]. Several studies have investigated the incidence and etiology of postoperative phrenic nerve dysfunction [2-6]. Whole body hypother- mia and ice-slush application around the heart have been implicated in the etiology [2,5-7]. Some studies investigating postoperative development of diaphragm elevation have shown diaphragm paralysis $[3,8]$. A few studies have reported preoperative and postoperative 
electrophysiological evaluations [4,5]. Efthimiou demonstrated that phrenic nerve injury developed in an ice-slush application group compared to a control group (no iceslush application) [2]. Sternal retraction, left internal mammary artery (LIMA) harvesting and central venous catheterization have also been implicated [5,6,9-11]. All studies had been performed in relation to cardiopulmonary bypass $(\mathrm{CPB})$ operations. There are no investigations in the literature concerning phrenic nerve injury in beating heart operations without $\mathrm{CPB}$, or other operations without thoracotomy such as peripheral artery surgery.

The present study was aimed at determining the incidence of phrenic nerve injury and differences among groups of patients who had undergone coronary artery bypass grafting (CABG) with $\mathrm{CPB}$, heart valve surgery, beating heart CABG without hypothermic CPB and peripheral arterial bypass surgery. Electrophysiological evaluation was carried out pre- and post-operatively. The peripheral vascular group was included in the study as a control group who did not need thoracotomy or sternotomy.

\section{Methods}

In this prospective, controlled clinical study, phrenic nerve electrophysiology was investigated bilaterally in 78 subjects undergoing cardiac or peripheral vascular surgery before and three weeks after surgery. Patients with diabetes mellitus or neurological disorders were excluded from the study.

In all cardiac procedures, central catheterization via the right internal jugular vein was preferred because left phrenic nerve injury is more common $[2-4,6]$. There was no central venous catheterization in patients who underwent peripheral vascular procedures.

All procedures were performed in the supine position; the right arm was near the body and the left arm was $90^{\circ}$ abducted to the body. The patients received standard intravenous anaesthesia with midazolam, etomidate, fentanyl citrate $(10-15 \mu \mathrm{g} / \mathrm{kg})$ and pancuronium $(0.1 \mathrm{mg} /$ $\mathrm{kg}$ ). In all CABGs (group 1) and valvular interventions (group 2), a cardiopulmonary bypass circuit was initiated with a roller pump and a non-pulsatile flow technique with a membrane oxygenator. During the bypass operation, moderate hypothermia (nasopharyngeal temperature $28^{\circ} \mathrm{C}$ ) and moderate hemodilution (hematocrit value 22 to $24 \%$ ) were used. For topical hypothermia during CPB, all patients received around 250-300 cc ice-slush (lactated Ringer's) around the heart within the pericardium after completion of each distal anastomosis (two or four times).

In the beating heart patients (group 3), CABG was performed without $\mathrm{CPB}$, cardiac arrest or ice-slush applica- tion. Following median sternotomy, distal coronary anastomoses were performed while the heart was working. In all CABG patients (except seven patients who had only vein grafts), LIMA was used in combination with saphenous grafts.

Peripheral vascular procedures included aorto-uni-femoral bypasses in five patients, aorto-bi-femoral in three patients (with laparotomy), and uni or bi-femoropopliteal bypasses in nine patients with synthetic polytetrafluoroethylene (PTFE) grafts under general anesthesia in the supine position.

\section{Electrophysiological Measurements of Phrenic Nerve}

Phrenic nerve conduction studies were performed bilaterally 1-2 days before and three weeks after surgery in all patients. In patients with injured phrenic nerves, followup studies were caried out at three months intervals thereafter. Subjects were studied lying supine, and the phrenic nerve was transcutaneously stimulated at the posterior border of the sternomastoid muscle in the supraclavicular fossa, just above the clavicle, using bipolar surface bar electrodes with the cathode placed caudally. Diaphragmatic compound muscle action potential (CMAP) was recorded with the surface electrodes applied to the seventh intercostal space in the anterior axillary line (G1 electrode) and eighth intercostal space along the lines (G2). The ground electrode was placed on the chest wall between the stimulating and recording electrodes. Two supramaximal responses were obtained and average values were calculated. Latency was determined from the onset of the negative peak, and amplitude was measured from the baseline to the negative peak.

\section{Ethics}

The study protocol was in accordance with the Helsinki Declaration of Human Rights and was approved by the local ethics committee of Trakya University, Medical Faculty (Session number, 10/03; date of decision, 29 May 2001). Written informed consent was obtained from each patient.

\section{Statistical Analysis}

Statistical analysis was performed using SPSS statistical software (SPSS Inc., Chicago, IL, USA). Continuous variables were expressed as the mean \pm standard deviation in the tables and values were compared using paired $t$-tests and Repeated Measure ANOVA tests. A p value $<0.05$ was considered statistically significant.

\section{Results}

Demographic and surgical data for all patients in each group are summarized in Table 1. Some differences were observed between groups, such as hypertension, 
Table I: Demographic and surgical data of all patients

\begin{tabular}{|c|c|c|c|c|}
\hline No. & $\begin{array}{l}\text { Group I } \\
\text { CABG with CPB } \\
n=38\end{array}$ & $\begin{array}{l}\text { Group } 2 \\
\text { Valve with CPB } \\
\mathrm{n}=1 \mathrm{I}\end{array}$ & $\begin{array}{l}\text { Group } 3 \\
\text { CABG beating heart } \\
n=12\end{array}$ & $\begin{array}{l}\text { Group } 4 \\
\text { Peripheral bypass } \\
n=17\end{array}$ \\
\hline Age, yr & $59 \pm 9$ & $51 \pm 10$ & $54 \pm 9$ & $46 \pm 12$ \\
\hline Male sex (\%) & 68 & 63 & 50 & 88 \\
\hline Hypertension (\%) & $63^{*}$ & 36 & 33 & 41 \\
\hline Smoker (\%) & 63 & $45^{*}$ & 83 & 88 \\
\hline $\mathrm{BSA}, \mathrm{m}^{2}$ & $1.78 \pm 0.13$ & $1.80 \pm 0.49$ & $1.72 \pm 0.13$ & $1.69 \pm 0.16$ \\
\hline$E F, \%$ & $53 \pm 15$ & $56 \pm 12$ & $52 \pm 12$ & 0 \\
\hline Grafts per patients & $2.4 \pm 0.6 *$ & 0 & $1.2 \pm 0.4$ & 0 \\
\hline Operation time, $\mathrm{min}$ & $283 \pm 62$ & $315 \pm 39$ & $235 \pm 29 *$ & $225 \pm 112^{*}$ \\
\hline CPB time, $\min$ & $101 \pm 24$ & $133 \pm 32$ & 0 & 0 \\
\hline $\mathrm{A} \times \mathrm{C}$ time, $\min$ & $56 \pm 17^{*}$ & $97 \pm 24$ & 0 & 0 \\
\hline IMA (\%) & 89 & 0 & 75 & 0 \\
\hline MV time, hr & $16 \pm 5$ & $13 \pm 4$ & $14 \pm 7$ & $4 \pm 3^{*}$ \\
\hline
\end{tabular}

Abbrevations are as follows: BSA, body surface area; $E F$, ejection fraction; CABG, coronary artery bypass grafting; CPB, cardiopulmonary bypass; $A X C$, aortic cross-clamp; IMA, internal mammary artery; MV, mechanical ventilation. ${ }^{*}=p<0.05$

Table 2: Phrenic nerve amplitude (mV)

\begin{tabular}{|c|c|c|c|c|}
\hline & \multicolumn{2}{|c|}{ Pre-operative } & \multicolumn{2}{|c|}{ post-operative } \\
\hline & Left & Right & Left & Right \\
\hline CABG with CPB $(n=35)$ & $0.33 \pm 0.25$ & $0.34 \pm 0.18$ & $0.28 \pm 0.17$ & $0.35 \pm 0.16$ \\
\hline Valv replacement with CPB $(n=9)$ & $0.27 \pm 0.11$ & $0.42 \pm 0.15$ & $0.26 \pm 0.09$ & $0.26 \pm 0.11$ \\
\hline CABG with beating heart $(n=12)$ & $0.35 \pm 0.29$ & $0.38 \pm 0.22$ & $0.25 \pm 0.15$ & $0.33 \pm 0.16$ \\
\hline Peripheral artery surgery $(n=17)$ & $0.59 \pm 0.56$ & $0.43 \pm 0.34$ & $0.47 \pm 0.46$ & $0.37 \pm 0.31$ \\
\hline
\end{tabular}

CABG, Coronary artery bypass grafting; CPB, Cardiopulmonary bypass No statistically significant differences were observed between groups and in the same groups, pre and postoperatively except five patients with phrenic injury $(p>0.05)$.

operation time, aortic cross clamp time (AXC), mechanical ventilation (MV) time etc.

Preoperative left and right phrenic nerve amplitudes and latency times were within normal limits and there were no statistically significant differences between the groups.

Three weeks after surgery, left phrenic nerve conduction was absent in three cases in group $1(8 \%$ in CABG with $\mathrm{CPB})$ and two cases in group 2 (18\% in valve replacement with $\mathrm{CPB}$ ). Left phrenic nerve dysfunction was observed in $10.2 \%$ (five of 49 patients) of the CPB with systemic hypothermia group. These five patients had elevation of the diaphragm and associated pathological motion. Normal left phrenic nerve conduction times were recorded from all the remaining patients (Table 2,3). Right phrenic nerve amplitude and latency time were within normal limits in both preoperative and postoperative evaluations of all patients, except the five patients with left phrenic nerve injury (Table 2, 3).
The patients in groups 1 and 2 were divided into a recordable phrenic nerve group $(\mathrm{n}=44)$ and a non-recordable phrenic nerve group $(n=5)$. There were no demographic or surgical differences between these two groups.

Three months later, left phrenic nerve function could observed electrophysiologically in one of the five patients in the non-recordable group. Phrenic nerve latency and amplitude were normal limits in this patient. Conduction was still absent from the left phrenic nerve in the other four patients six months and twelve months later.

\section{Discussions}

Although observation of elevated diaphragm on a chest radiogram and diphragmatic motion on ultrasound are valuable methods for assessing phrenic nerve injury, the best evaluation method is electrophysiological $[3,5,13]$. Moreover, we routinely followed up diaphragm elevation with $\mathrm{x}$-ray investigation and fluoroscopy. Since diaphragm elevation is not correlated with phrenic nerve injury (subpulmonic effusion, subphrenic collection, atel- 
Table 3: Phrenic nerve latency (ms)

\begin{tabular}{lllll}
\hline & $\begin{array}{l}\text { Pre-operative } \\
\text { Left }\end{array}$ & Right & $\begin{array}{l}\text { Post-operative } \\
\text { Left }\end{array}$ & Right \\
\hline CABG with CPB $(n=35)$ & $7.53 \pm 0.87$ & $7.97 \pm 0.91$ & $7.68 \pm 0.11$ & $7.87 \pm 1.24$ \\
Valv replacement with CPB $(n=9)$ & $7.92 \pm 0.98$ & $7.75 \pm 1.01$ & $7.95 \pm 1.01$ & $8.4 \pm 1.14$ \\
CABG with beating heart $(n=12)$ & $7.51 \pm 1.09$ & $6.78 \pm 1.07$ & $7.63 \pm 0.58$ & $7.48 \pm 0.45$ \\
Peripheral artery surgery $(n=17)$ & $7.04 \pm 0.91$ & $7.06 \pm 0.81$ & $7.41 \pm 0.86$ & $7.1 \pm 0.85$ \\
\hline
\end{tabular}

CABG, Coronary artery bypass grafting; $C P B$, Cardiopulmonary bypass No statistically significant differences were observed between groups and in the same groups, pre and postoperatively except five patients with phrenic injury $(p>0.05)$.

ectasia etc), these findings were excluded from the study. The main purpose of the control electrophysiological evaluation at the end of the third postoperative week was to detect patients with true axonal degeneration. More patients with phrenic nerve injury could be identified if evaluation were performed earlier in the postoperative period.

The main finding in this study was postoperative loss of left phrenic nerve conduction in five patients. All the left phrenic nerve dysfunction cases were in the hypothermic cardiopulmonary bypass groups ( 3 in $C A B G$ with $C P B$ and 2 in heart valve replacement with $C P B$ ). No phrenic nerve dysfunction was observed in beating heart CABG or peripheral arterial bypass grafting patients. This result supports the conclusion that hypothermic cardiopulmonary bypass and ice-slush application around the heart may be related to phrenic nerve dysfunction. This inference is in accordance with other studies in the literature $[2,5-7]$.

No phrenic nerve dysfunction was observed in the normothermic beating heart group; the majority of patients in this group were LIMA harvested. This supports the view that LIMA harvesting and sternotomy do not play any role in phrenic nerve injury. Also, no phrenic nerve injury was observed in the peripheral arterial bypass group, supporting the conclusion that phrenic nerve injury is mostly associated with the conditions of hypothermic cardiac surgery.

A few electrophysiological studies of cardiac surgery patients have been published, but no comprehensive evaluation including all etiological factors has been reported. In particular, no previous study has included beating heart CABGs or other vascular interventions as control groups. In our study, hypothermic cardiopulmonary bypass and beating heart surgery were compared. Phrenic nerve latency time amplitude following surgery were in accordance with reports in the literature [13-16].
Axonal damage and demyelination are accepted as causes of reversible or irreversible injury of the phrenic nerve $[2,3,5,6]$. We were supposed that the refractory nerve lesions in four patients were severe axonal damage and irreversible because of the lesions were not improved during one year. Because of the unilateral lesion and there was not dyspnea in these patients, surgical diaphragmatic plication was not considered. Nerve lesion in other one patient was thought due to conduction block and for this reason it was recovered within three months.

Left phrenic nerve damage is more frequent than right, and in this study all the injured nerves were left ones [2$4,6,13]$. However, both left and right nerves have been equally exposed to cardiopulmonary bypass and systemic hypothermia, suggesting that the hypothermic cardiopulmonary bypass is not itself the cause of the damage. Two possible explanations remain for the etiology. One is the topical cardiac cooling; the other is the LIMA harvesting. LIMA harvesting has also been implicated in phrenic nerve injury in the literature $[5,6,10]$. However, we observed no nerve injury in our beating heart CABG group, most of whom were LIMA harvested. Moreover, our beating heart results do not support the opinion that sternal retraction causes phrenic nerve injury $[6,12]$.

If topical cardiac cooling is the major cause of phrenic nerve injury, why is the frequency of injury to left and right nerves not similar? It is common knowledge that the left ventricle is the major target for myocardial protection in open heart surgery. For this reason, both cardioplegia and topical cooling frequently orientate to the left ventricle. Ice-slush especially is applied around the left ventricle and into the left portion of the pericardial cavity. Thus, the right phrenic nerve is frequently preserved from cold inury.

Some studies have suggested that phrenic nerve conduction velocity is slowed by cooling $[3,4,6,7]$. In this study, we observed no statistically significant slowing in bilateral phrenic nerve velocity between preoperative and postoperative evaluation, except in five patients. Furthermore, 
the phrenic nerve amplitudes were not different, contrary to claims in the literature $[6,7]$.

Bilateral phrenic nerve injury has been reported to aggravate respiratory distress and prolong mechanical ventilation, but in no case did we observe bilateral nerve injury. Postoperative respiratory functions were not affected in our patients with unilateral phrenic nerve injury: mechanical ventilation times were similar in the phrenic nerve injury group and the normal phrenic function group [1719].

\section{Conclusions}

Our results support the view that ice-slush application around the heart causes the phrenic nerve injury following cardiac surgery. It is recommended that instead of iceslush application, mildly cooled saline be applied to the pericardial cavity. Also, an insulated pad may be used in cases in which ice-slush is applied around the heart $[6,20]$.

\section{Competing interest}

None declared.

\section{Authors' contributions}

Suat Canbaz; study design, data analysis and writing.

Nilda Turgut; data collection, data analysis.

Umit Halici; data collection.

Kemal Balci; data collection.

Turan Ege; data analysis.

Enver Duran; study design, data analysis.

\section{References}

I. Tripp HF, Bolton JW: Phrenic nerve injury following cardiac surgery: a review. J Card Surg 1998, 13(3): 18-23.

2. Efthimiou J, Butler J, Woodham C, Benson MK, Westaby S: Diaphragm paralysis following cardiac surgery: role of phrenic nerve cold injury. Ann Thorac Surg I99I, 52(4): 1005-8.

3. DeVita MA, Robinson LR, Rehder J, Hattler B, Cohen C: Incidence and natural history of phrenic neuropathy occuring during open heart surgery. Chest 1993, 103(3):850-6.

4. Chroni E, Patel RL, Taub N, Venn GE, Howard RS, Panayiotopoulos $\mathrm{CP}$ : A comprehensive electrophysiological evaluation of phrenic nerve injury related to open-heart surgery. Acta Neurol Scand 1995, 9 I (4):255-9.

5. Dimopoulou I, Daganou M, Dafni U, Karakatsani A, Khoury M, Geroulanos S, Jordanoglou J: Phrenic nerve dysfunction after cardiac operations: Electrophysiologic evaluation of risk factors. Chest 1998, II3(1):8-14.

6. Mazzoni M, Solinas C, Sisillo E, Bortone F, Susini G: Intraoperative phrenic nerve monitoring in cardiac surgery. Chest 1996, 109(6): | 455-60.

7. Mills GH, Khan ZP, Moxham J, Desai J, Forsyth A, Ponte J: Effects of temperature on phrenic nerve and diaphragmatic function during cardiac surgery. $\mathrm{Br} J$ Anaesth 1997, 79(6):726-32.

8. Sarnowski W, Kulesza J, Ponizynski A, Dyszkiewicz W: Elevation of the diaphragma after cardiac surgery. Pol Merkuriusz Lek 200I, I0(55):24-6.
9. Tripp HF, Sees DW, Lisagor PG, Cohen DJ: Is phrenic nerve dysfunction after cardiac surgery related to internal mammary harvesting? J Card Surg 200 I, I6(3):228-3I.

10. O'Brien JW, Johnson SH, VanSteyn SJ, Craig DM, Sharpe RE, Mauney MC, Smith PK: Effects of internal mammary artery dissection on phrenic nerve perfusion and function. Ann Thorac Surg 1991, 52(2): $182-8$.

II. Berrizbeitia LD, Tessler S, Jacobowitz IJ, Kaplan P, Budzilowicz L, Cunningham JN: Effect of sternotomy and coronary bypass surgery on postoperative pulmonary mechanics. Chest 1989, 96(4):873-6.

12. Cruz-Martinez A, Armijo A, Fermoso A, Moraleda S, Mate I, Marin M: Phrenic nerve conduction study in demyelinating neuropathies and open heart surgery. Clin Neurophysiol 2000, I I I (5):82-5.

13. Mills GH, Kyroussis D, Hamnegard CH, Wragg S, Moxham J, Green $\mathrm{M}$ : Unilateral magnetic stimulation of the phrenic nerve. Thorax 1995, 50(I I): I I62-72.

14. Markand ON, Kincaid JC, Pourmand RA, Moorthy SS, King RD, Mahomed Y, Brown JW: Electrophysiologic evaluation of diaphragm by transcutaneous phrenic nerve stimulation. Neurology 1984, 34(5):604-14.

15. Mier A, Brophy C, Moxham J, Green M: Phrenic nerve stimulation in normal subjects and in patients with diaphragmatic weakness. Thorax 1987, 42( I I ):885-8.

16. Markand ON, Moorthy SS, Mahomed Y, King RD, Brown JW: Postoperative phrenic nerve palsy in patients with open-heart surgery. Ann Thorac Surg 1985, 39:68-73.

17. Hoch B, Zschocke A, Barth H, Leonhardt A: Bilateral diaphragmatic paralysis after cardiac surgery: ventilatory assistance by nasal mask continuous positive airway pressure. Pediatr Cardiol 200I, 22(I):77-9.

18. Werner RA, Geiringer SR: Bilateral phrenic nerve palsy associated with open-heart surgery. Arch Phys Med Rehabil 1990, $7 I(12): 100-2$.

19. Efthimiou J, Butler J, Benson MK, Westaby S: Bilateral diaphragm paralysis after cardiac surgery with topical hypothermia. Thorax I99I, 46(5):35I-4.

20. Esposito RA, Spencer FC: The effect of pericardial insulation on hypothermic phrenic nerve injury during open-heart surgery. Ann Thorac Surg 1987, 43(3):303-8.

\section{Pre-publication history}

The pre-publication history for this paper can be accessed here:

http://www.biomedcentral.com/1471-2482/4/2/prepub

Publish with Biomed Central and every scientist can read your work free of charge

"BioMed Central will be the most significant development for disseminating the results of biomedical research in our lifetime. "

Sir Paul Nurse, Cancer Research UK

Your research papers will be:

- available free of charge to the entire biomedical community

- peer reviewed and published immediately upon acceptance

- cited in PubMed and archived on PubMed Central

- yours - you keep the copyright 